DOI: https://doi.org/10.21721/p2p.2019v6n1.p224-243

INOVAÇÃO

\title{
BIBLIOTECÁRIOS EM HOSPITAIS: COMPETÊNCIA COMUNICATIVA E APRENDIZAGEM
}

\author{
Clóvis Ricardo Montenegro de Lima ${ }^{1}$ \\ IBICT \\ clovismlima@gmail.com \\ Helen Gunther Fischer ${ }^{2}$ \\ UNISUL \\ helen.fg@gmail.com \\ Kátia Simões ${ }^{3}$ \\ INCA \\ katia.simoes@gmail.com \\ Márcio Finamor ${ }^{4}$ \\ marciofinamor@gmail.com
}

\begin{abstract}
Resumo
Este artigo aborda o trabalho do bibliotecário em hospitais a partir da teoria do agir comunicativo de Jürgen Habermas e de pesquisa de campo. Metodologicamente, trata-se de pesquisa qualiquantitativa com coleta de dados primários junto a 26 bibliotecários clínicos. Apresenta as interações mediadas pela linguagem, que demandam competência comunicativa, e estabelece relação entre Discurso e aprendizagem. O agir comunicativo é caracterizado como base para a problematização com evidências científicas em hospitais. Os dados coletados apontam que os profissionais bibliotecários reconhecem a importância de seu trabalho como apoio à equipe médica. No entanto, a competência comunicativa dos bibliotecários não pode estar focada apenas na recuperação de informação em equipes orientadas por evidências científicas. Para integridade do processo discursivo, os bibliotecários são convidados a intervir de modo crítico. Conclui-se que esse profissional é o elo entre a informação científica e as práticas cotidianas hospitalares, intensificando e dinamizando as práticas sociais e comunicativas e que realizar o trabalho com a informação científica em saúde é uma forma de cuidar da saúde do paciente. Por fim, evidencia-se que o acesso à informação qualificada e a construção de entendimento permitem suporte efetivo à conduta em prol da saúde.
\end{abstract}

Palavras-chave: Bibliotecário Hospitalar. Competência Comunicativa. Discurso. Aprendizagem.

\section{LIBRARIANS IN HOSPITALS: COMMUNICATIVE COMPETENCE AND LEARNING}

\begin{abstract}
The article approaches the work of the librarian in hospitals based on the theory of communicative acting by Jürgen Habermas and field research. Methodologically, this is a qualiquantitative research with primary data collection from 26 clinical librarians. It presents language-mediated interactions that demand communicative competence and establishes a relationship between Discourse and learning. It characterizes communicative acting as the basis for problematization with scientific evidence in hospitals. The data collected indicate that librarians recognize the importance of their work as a support to the medical team. However, the communicative competence of librarians cannot be focused just on information retrieval in scientific evidence-driven teams. For the integrity of the discursive process, librarians are invited to intervene critically. It is concluded that this professional is the link between scientific information and daily hospital practices, intensifying and dynamizing social and communicative practices and that performing work with scientific health information is a way to take care of the patient's health. Finally, it is evident that the access to qualified information and the construction of understanding allow effective support for clinical practices.
\end{abstract}

Keywords: Hospital Librarian. Communicative Competence. Discourse. Learning.

\footnotetext{
${ }^{1}$ Doutor em Administração e em Ciência da Informação. Pesquisador do IBICT.

${ }^{2}$ Doutora em Engenharia e Gestão do Conhecimento. Pesquisadora e Docente da Universidade do Sul de Santa Catarina (UNISUL).

${ }^{3}$ Mestre em Biblioteconomia. Bibliotecária do INCA.

${ }^{4}$ Mestre em Ciência da Informação.
} 


\section{INTRODUÇÃO}

Neste artigo discute-se o agir do bibliotecário em hospitais a partir da teoria do agir comunicativo de Jürgen Habermas. As interações mediadas pela linguagem, os gestos e os ritos fazem parte de uma competência comunicativa, que ganha uma forma especial no Discurso que problematiza e reconstrói racionalmente. Este agir tem contornos éticos e morais que estão relacionados a discutir, deliberar e fazer.

O agir comunicativo em Jürgen Habermas é a materialidade do uso social da linguagem, que representa as coisas e os fatos do mundo da vida, expressa intenção e interesses, ao mesmo tempo em que integra socialmente e socializa. A competência comunicativa é mais do que a mera competência linguística, de representar e expressar. Ela inclui a capacidade de problematizar, de reconstruir racionalmente, de aprender. A aprendizagem tem dimensões subjetivas e intersubjetivas.

A aprendizagem é uma reconstrução racional sempre em um contexto intersubjetivo. A aprendizagem na medicina implica em, nas belas palavras de Michel Foucault (1987, p. 122), "ver uma linguagem quando se presencia um espetáculo". Paulo Freire (1985), põe o problema no centro da aprendizagem, que é crítica e racional.

Os bibliotecários entraram nos hospitais pelas bibliotecas de medicina. Fizeram experiências e descobriram evidências empíricas da potência terapêutica dos livros. Têm sido convidados para compor equipes multiprofissionais de clínica e de pesquisa, para colaborar em tarefas que incluem a pesquisa bibliográfica, a busca de evidências científicas para basear a medicina, a identificação de referências dentro das controvérsias éticas, a normalização da comunicação científica e a organização do conhecimento para acesso aberto.

O agir dos bibliotecários em hospitais pode ter em comum as características da competência comunicativa que estão orientadas para o Discurso: a problematização e a reconstrução racional. Assim, cabe formar bibliotecários que tenham competências de trabalhar com conflitos, de crítica, de conversar com base em argumentos, de construir e reconstruir acordos. Isto dá o contorno do bibliotecário hospitalar, que faz mais do que clínica ou medicina, e age como um educador.

\section{O AGIR DO BIBLIOTECÁRIO EM HOSPITAIS}

A presente pesquisa caracteriza-se como quantitativa e descritivo-exploratória, com coleta de dados primários e análise estatística simples. A investigação sobre o agir dos 
bibliotecários dentro dos hospitais e das equipes multiprofissionais de saúde envolveu aplicação de questionário com escala Likert de cinco pontos (Concordo totalmente, Concordo, Não tenho opinião, Discordo e Discordo fortemente). Utilizou-se a ferramenta Google Docs, selecionada para elaboração das perguntas, interação e respostas.

Obteve-se um total de (26) respostas de participantes bibliotecários do Estado do Rio de Janeiro, que trabalham em Biblioteca Virtual em Saúde (BVS) ou são membros da Associação dos Profissionais de Informação (APCIS) (Gráfico 1):

Gráfico 1- Local de trabalho dos respondentes

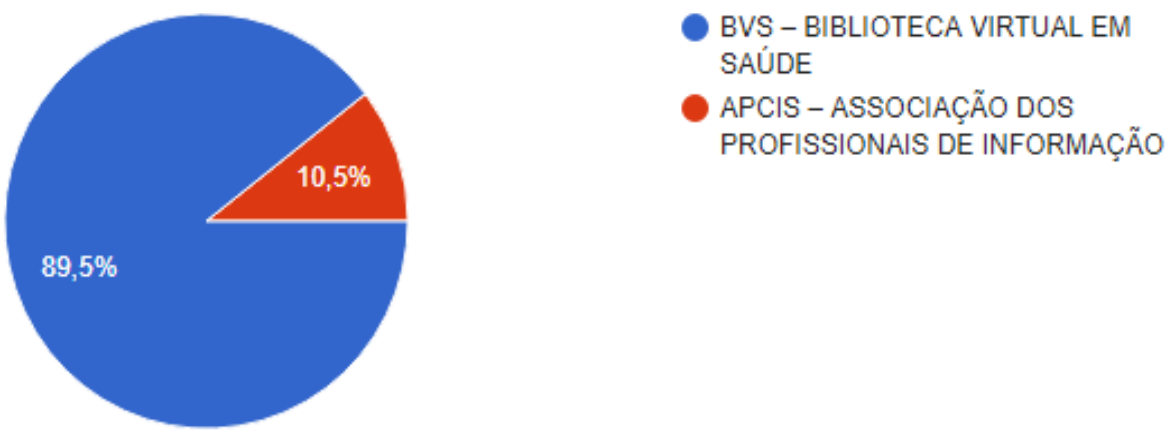

Fonte: Dados primários. Elaborado pelos autores, 2019

Os bibliotecários respondentes possuem nível de escolaridade de graduação (38,5\%), de especialização $(34,6 \%)$ ou de mestrado $(23,1 \%)$. 61,5\% dos informantes continuaram os estudos e a formação após concluírem curso de graduação.

Gráfico 2 - Grau de instrução dos respondentes

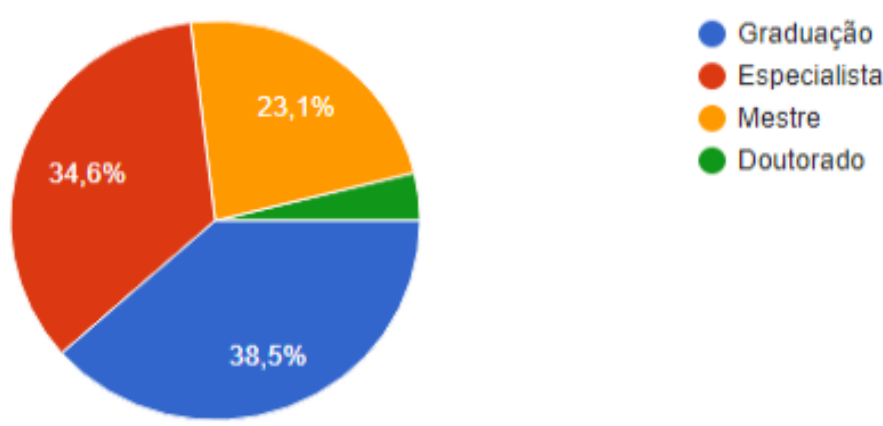

Fonte: dados primários. Elaborado pelos autores, 2019

No gráfico abaixo, observa-se que os profissionais bibliotecários consultados possuem uma vasta experiência no cenário hospitalar. A maioria possui mais de 10 anos de experiência. 
Gráfico 3 - Tempo de carreira dos bibliotecários

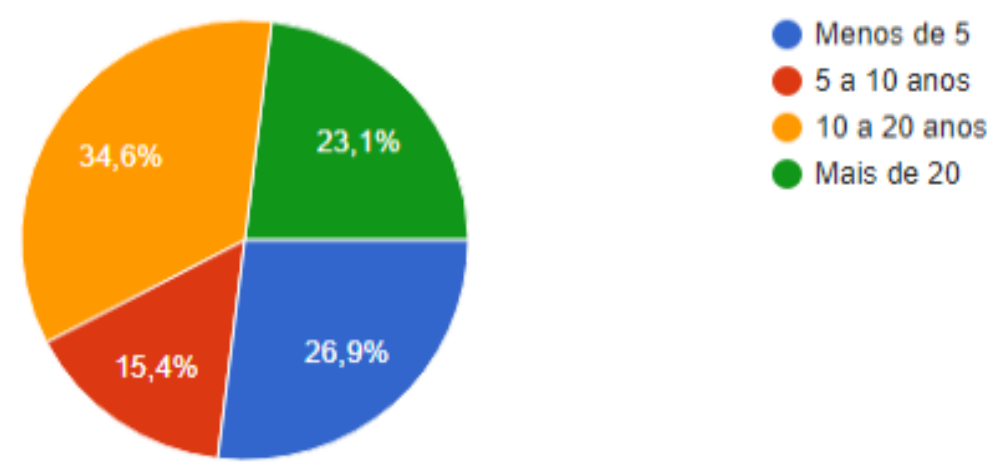

Fonte: dados primários. Elaborado pelos autores, 2019

Além de caracterizar os respondentes, as duas próximas seções apresentam os dados relacionados ao uso da informação de caráter científico no contexto hospitalar e ao trabalho dos bibliotecários nessas organizações.

\subsection{A INFORMAÇÃO CIENTÍFICA EM HOSPITAIS}

O bibliotecário precisa acompanhar a modernização tecnológica, apreender novas competências integradoras e se unirem às equipes multiprofissionais em diversos ambientes de trabalho. Dentro desses parâmetros, necessitam estar atentos ao novo e procurar fazer o seu melhor no que tange o seu ofício. Na medicina, a cada instante, surgem novas pesquisas, novas atualizações e modernização nas cirurgias, sendo criadas, apreendidas e testadas, ou seja, os profissionais de saúde em geral devem estar em constante renovação no cenário científico. E é essa conclusão que os especialistas concordam plenamente na atualização e na relevância da informação científica no cuidado de saúde e a importância do profissional capacitado para tal êxito, conforme mostra o gráfico 4.

Gráfico 4 - É relevante e pertinente o trabalho com a informação científica e sua disseminação no ambiente hospitalar

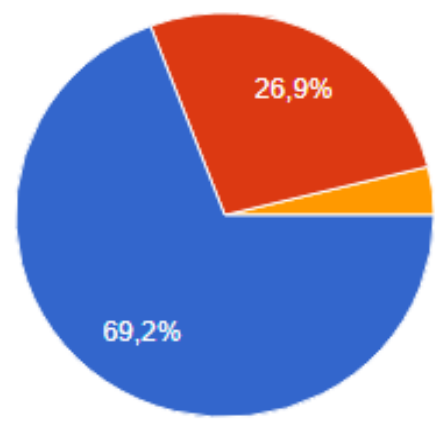

Concordo totalmente

Concordo

Não tenho opinião

Discordo

Discordo fortemente

Fonte: dados primários. Elaborado pelos autores, 2019 
O trabalho realizado pelos bibliotecários atende diretamente os serviços informacionais requeridos no contexto hospitalar, além de antecipar as lacunas das necessidades informacionais, tanto dos médicos quanto dos pacientes. Os bibliotecários pesquisados concordam plenamente que a qualidade do trabalho em saúde é influenciada pela informação científica (gráfico 5).

Gráfico 5 - Organização, oferta e uso da informação científica interferem na qualidade do trabalho em saúde

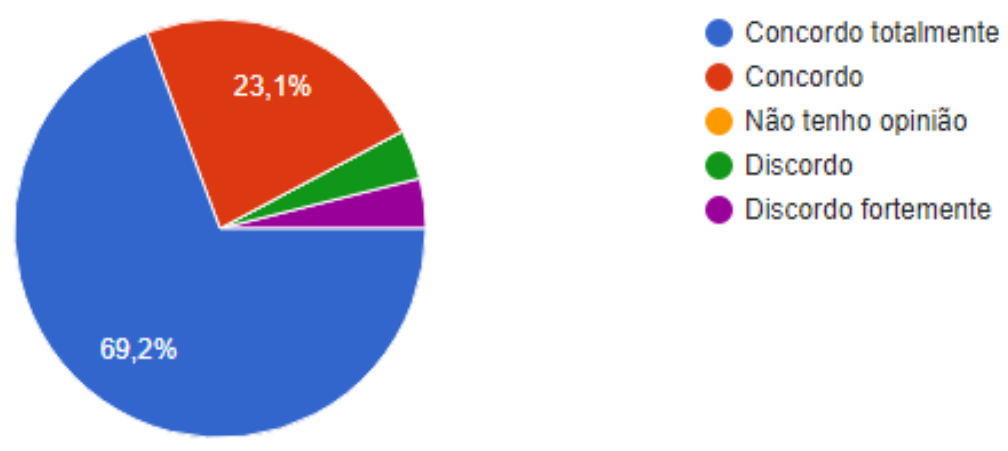

Fonte: dados primários. Elaborado pelos autores, 2019

Os respondentes concordam plenamente que encontrar a melhor evidência cientifica, através do apoio do bibliotecário, pode auxiliar a equipe médica a salvar vidas e manter a qualidade da informação na resolução e diagnóstico dos casos, conforme retrata a gráfico 6.

Gráfico 6 - A informação científica melhora a qualidade dos casos clínicos
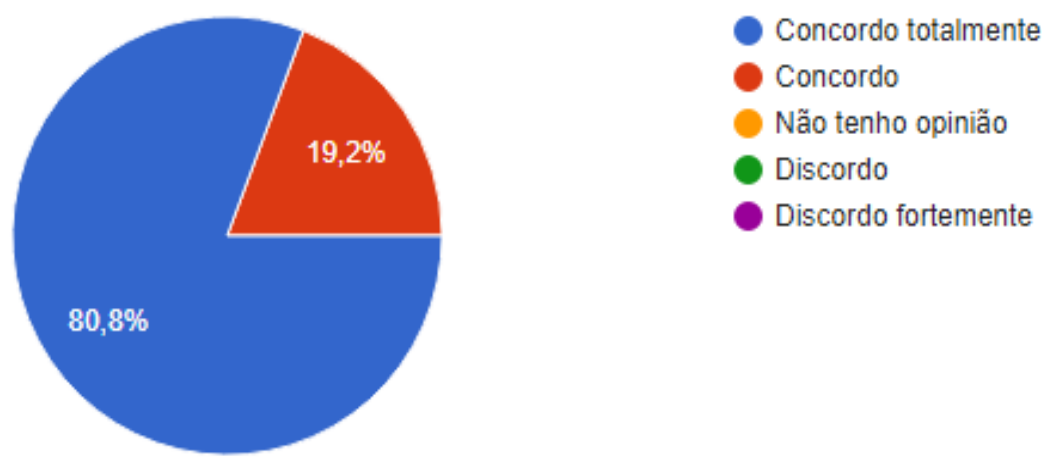

Fonte: dados primários. Elaborado pelos autores, 2019

Sobre a questão da busca de informação relevante, atual, de fácil acesso para não perder tempo e recursos. O bibliotecário surgiria como esse profissional para facilitar a equipes de saúde (gráfico 7). 
Gráfico 7 - O profissional de saúde que está informado age com mais segurança

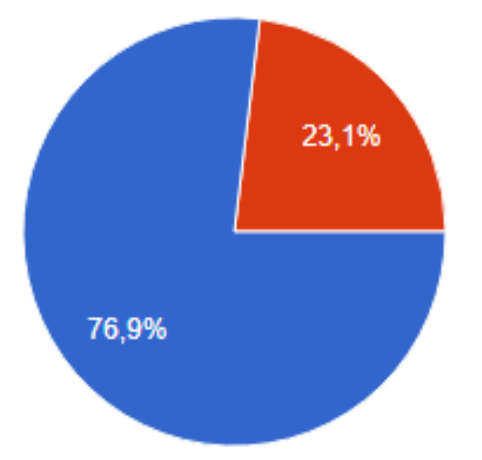

Concordo totalmente

Concordo

Não tenho opinião

Discordo

Discordo fortemente

Fonte: dados primários. Elaborado pelos autores, 2019

\subsection{O TRABALHO DO BIBLIOTECÁRIO EM HOSPITAIS}

O bibliotecário na equipe médica pode ser um diferencial para os hospitais, equipes de saúde e o sistema de saúde. Um desses fatores é a aquisição das competências necessárias para o trabalho com a informação em saúde e equipes, como também, boas ferramentas, serviços e fontes de informação e bases de dados disponíveis para sua pesquisa nos preceitos da relevância e qualidade da informação. Neste sentido, as equipes especialistas concordam plenamente sobre tal atividade e necessidade como mostra o gráfico 8 .

Gráfico 8 - O trabalho com a informação científica pode ser mais eficaz se feito por um bibliotecário.

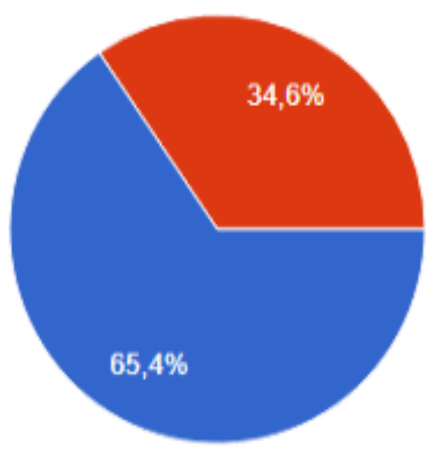

Concordo totalmente

Concordo

Não tenho opinião

Discordo

Discordo fortemente

Fonte: Dados primários. Elaborado pelos autores, 2019

Com relação às habilidades e competências técnicas e de gestão o bibliotecário pode facilitar e agilizar o acesso, recuperação, compartilhamento e uso da informação em seu melhor formato e disseminação para a equipe em saúde. Assim, especialistas em sua maioria concordam em tal questão de acordo com o gráfico 9. 
Gráfico 9 - O tempo de busca e recuperação da informação pode ser otimizado com o bibliotecário.

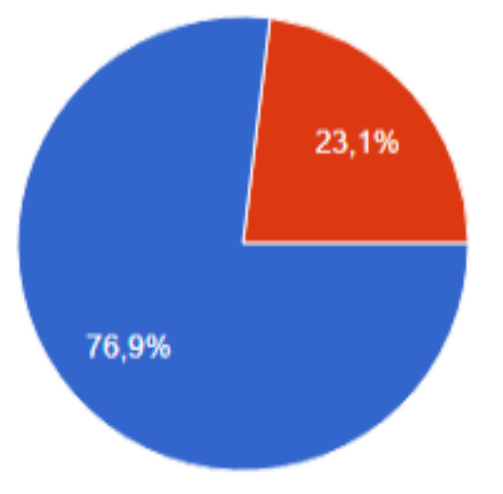

Concordo totalmente

Concordo

Não tenho opinião

Discordo

Discordo fortemente

Fonte: dados primários. Elaborado pelos autores, 2019

No que diz respeito a mediação da informação, o bibliotecário pode aprimorar a qualidade da comunicação científica no atendimento em hospitais, conforme os especialistas concordam:

Gráfico 10 - O bibliotecário pode melhorar a qualidade da comunicação científica em hospitais.

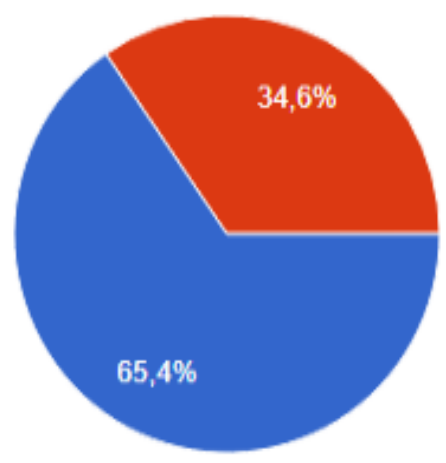

Fonte: dados primários. Elaborado pelos autores, 2019

Especialistas concordam totalmente em incluir o bibliotecário na equipe médica e de saúde no Brasil. No apoio as pesquisas e procura de evidências médicas para tomada de decisão e diagnóstico, e no apoio e assistência informacional aos pacientes. Apoiando os médicos e gerando, dessa forma, mais tempo para os profissionais de saúde cuidar dos pacientes de uma forma segura. Com aponta os dados abaixo: 
Gráfico 11- É necessário incluir o bibliotecário no ambiente hospitalar no Brasil.

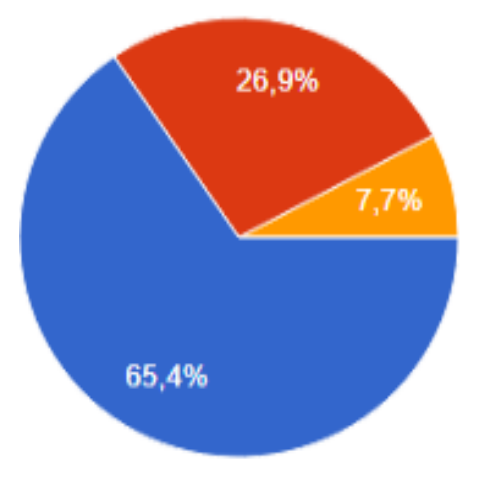

Concordo totalmente

Concordo

Não tenho opinião

Discordo

Discordo fortemente

Fonte: dados primários. Elaborado pelos autores, 2019

Especialistas sabendo das atividades e competências dos bibliotecários e no caso se tivessem no papel de diretores de hospitais incluiria esses profissionais na equipe de saúde, como mostra o Gráfico 12.

Gráfico 12 - Se você fosse diretor de um hospital incluiria bibliotecários na equipe de saúde?

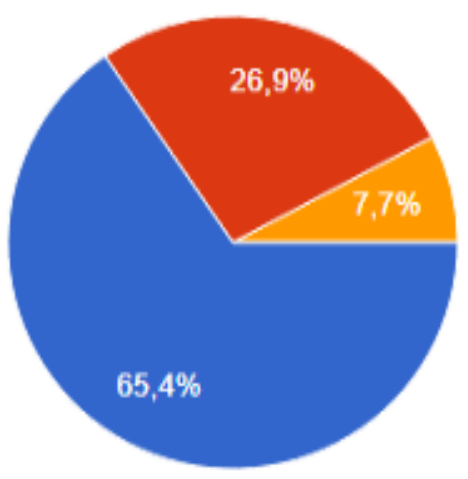

Concordo totalmente

Concordo

Não tenho opinião

Discordo

Discordo fortemente

Fonte: dados primários. Elaborado pelos autores, 2019

\section{AGIR COMUNICATIVO, COMPETÊNCIA COMUNICATIVA E APRENDIZAGEM}

O agir comunicativo é a interação mediada pela linguagem, além de gestos e ritos nas relações intersubjetivas. $\mathrm{O}$ agir comunicativo constrói identidade, cria vínculos entre as pessoas e constitui os grupos. Através do agir comunicativo os falantes erguem pretensões de validade para entendimento e acordos. O conceito e a prática do agir comunicativo refere-se à interação de pelo menos dois sujeitos capazes de falar e agir estabelecendo uma relação interpessoal (seja por meios verbais ou extraverbais). Os atores buscam um entendimento da situação para, de 
maneira concordante, coordenar seus planos de ação e, com isso, suas ações (HABERMAS, 2012, p. 166).

Quando os falantes enfrentam uma controvérsia eles podem usar uma forma especial de agir comunicativo: o Discurso. No discurso os falantes apresentam proposições para validação e legitimação através do jogo de linguagem argumentativo. Os falantes que se entendem podem construir acordos com pretensão de validade universal para todos os concernidos.

A ação comunicativa e com a prática dialógica estabelecem pretensões de validade e normatividade congêneres. O agir profissional do bibliotecário nas organizações de saúde requer práticas comunicativas, éticas e atitudinais (competências), por seu agir tratar-se de um ambiente hospitalar complexo por exigência da situação vivida onde acontecem excessivas relações de cuidados, de sentimentos, de informações sobre a vida e acontecimentos do paciente, de pensamentos e atitudes humanas.

O processo dialógico é resultante e promotor de ação de compartilhamento de informações situada no plano de ação dependente da interação. A informação, nesse caso, é produzida, organizada, acessada e apropriada no processo de encontro com o outro. O outro que produz, o outro que organiza, disponibiliza, facilita o acesso e uso, mas que também constrói e oferta dispositivos facilitadores do encontro e do debate com os outros, ampliando nossas interpretações alocadas na intersubjetividade. Sobre as relações estabelecidas com os outros no desenvolvimento do processo de apropriação da informação, entende-se aqui a apropriação ou mediação como o processo por meio do qual podemos conferir significado à informação e dar sentido às nossas próprias vidas, atitudes e fazeres laborais (GOMES; VARELA, 2016).

A prática e a aplicabilidade de conceitos humanísticos e ação social requer maiores esforços éticos e morais para os sujeitos, além de práticas que visem à construção de vínculos afetivos e efetivos sobre ações que resultem em bem-estar dos envolvidos, no sentido existencial, e melhoria das práticas de comunicação e de aprendizagem. Assim, o agir social e racional das práticas informacionais do bibliotecário, em ações de repensar e discutir a sua ação dentro do ambiente hospitalar. Reconfigurando em ações que favorecem o desenvolvimento de processos de capacitação e aprendizagem por meio da intersubjetividade entre sujeitos capazes de falar e de agir na dinâmica comunicacional e nas ações práticas informacionais em ambientes contemporâneos e complexos: como o hospital.

O processo comunicacional e do agir comunicativo está ancorado em uma concepção construtivista da aprendizagem na medida em que compreende a formação discursiva da vontade e a argumentação em geral como formas de reflexão do agir comunicativo e na medida 
em que exige uma mudança de atitude. Da a argumentação encerra algo de antinatural: o rompimento com a ingenuidade das pretensões de validade, erguidas diretamente, e cujo reconhecimento intersubjetivo depende da prática comunicativa cotidiana. $\mathrm{Na}$ argumentação, as pretensões de validade pelas quais os agentes se orientam sem problemas na prática cotidiana são tematizadas e problematizadas. A aprendizagem significa que a pessoa transforma de tal maneira as estruturas cognitivas disponíveis, que consegue resolver melhor do que anteriormente a mesma espécie de problemas e conflitos (HABERMAS, 1989, p. 155-156 apud LIMA; LIMA; MOREIRA, 2019, p. 60, grifo nosso).

$\mathrm{Na}$ atualidade é preciso maior reflexão crítica sobre as atividades profissionais do bibliotecário, como também, as formas e modos de comunicação em geral, no que tange as relações, trocas de interações e informações na perspectiva das diversidades direcionada na racionalidade comunicativa. Isto é, as práticas do profissional bibliotecário ancorado sob o olhar dos processos de gerenciamento organizacional e das relações sociais com o viés humanístico. Nessa perspectiva procurar apresentar os benefícios que a incorporação de um modelo social e interacionista aos quadros hospitalares podendo proporcionar modelos como ações engajadoras e deliberativas para o desenvolvimento organizacional, profissional e pessoal (emancipatório e de aprendizagem). Tornando-se de grande importância para uma amplificação da ótica tradicional da formação dos bibliotecários que restringe o seu agir a de um facilitador da relação com a informação e comunicação científica como agente organizador, mediador e inovador nos serviços e produtos informacionais em saúde. Quesitos esses relevantes para a prática do bibliotecário e da "competência comunicativa". Tal possibilidade só será efetiva com o aperfeiçoamento e a aprendizagem destas competências e com a aquisição mais profunda da teoria humanista.

Nas palavras de Habermas a racionalidade comunicativa traz consigo conotações que, no fundo, retrocedem à experiência central da força espontaneamente unitiva e geradora de consenso própria à fala argumentativa (competência linguística) em que diversos participantes superam suas concepções inicialmente subjetivas para, então, graças à concordância de convicções racionalmente motivadas, assegurar-se ao mesmo tempo da unidade do mundo objetivo e da intersubjetividade de seu contexto vital (HABERMAS, 2012, p. 37).

Com os novos meios de comunicação, práticas informacionais e uma nova ordem de organização social, as chamadas sociedades complexas e as fragilidades das relações interpessoais, as habilidades administrativas e competências administrativas necessitam ser remodeladas em competências humanísticas e integradoras precisam ser tanto reforçadas quanto modificadas. Quanto a essas aptidões, a competência requerida do bibliotecário é maior 
do que uma acumulação de teorias e metodologias da administração instrumental e técnica. Elas são necessárias, mas não são suficientes. Há outra competência racional integradora: comunicativa, argumentativa e discursiva, que é a competência comunicativa. Habilidade essa que pode ser aprendida e aperfeiçoada e na qual esse profissional está à disposição para argumentação e discussão, não apenas para escolhas racionais. Esta opção normativa pela escuta do outro e do debate consensual é importante para uma crítica da administração instrumental e das práticas do bibliotecário (SILVA; FERNANDES; LIMA, 2013, p. 129-130, grifo nosso).

A competência comunicativa é a competência linguística, mas não somente ela. Em primeiro lugar porque a comunicação não é apenas uso da linguagem, mas inclui gestos e ritos. Além disto, ela deve incluir a competência para a forma Discurso: problematização e reconstrução racional ("racionalidade comunicativa"). A problematização é o primeiro passo para a aprendizagem e o desenvolvimento moral. A capacidade de fazer crítica é fundamental para a aprendizagem e pode ela mesma ser aprendida. A aprendizagem é reconstrução racional, pois implica em ir além do que está dado. Ela possibilita escolhas, debates e ações de manutenção, melhorias e inovação.

$\mathrm{O}$ uso da linguagem e da competência comunicativa é fator importante para o bibliotecário adquirir, visam atos comunicativos nas relações humanas com práticas agenciadas à razão comunicativa: exigência das relações intersubjetivas. Por isso:

Reforçamos que Habermas procura, no interior da linguagem, o norte da razão
comunicativa que defende existir. É no uso social que os sujeitos fazem da linguagem
como forma de comunicação, que se estabeleceriam os elementos para a construção
de uma racionalidade comunicacional. A racionalidade, para Habermas, é uma forma
de coordenação de ação coletiva mediada pela linguagem, por isso, ele relaciona a
intersubjetividade às estruturas de comunicação e à integração social. Todavia,
"acima" das açães racionais haveria, segundo Habermas, uma força emancipatória
que conduziria o uso dessa razão e que se estabelece, se institui e se manifesta na
intersubjetividade comunicativa entre sujeitos, em uma ação de comunicação. Esta
ação, por sua vez, tem como objetivo um entendimento mútuo entre os atores da
comunicação. A integração social, portanto, se dá mediada pela linguagem
(HABERMAS, 2002 apud GRACIOSO, 2009).

Com isso, a difusão e o compartilhamento de informações e conhecimentos requerem a conexão entre os atores, com canais ou mecanismos de comunicação que propiciem fluxos de conhecimento e o aprendizado interativo. Observa-se que as organizações e os agentes que cooperam introduzem maior número de melhorias e de inovações do que os que não cooperam, e o grau de melhoria e de inovação aumenta com a variedade de parceiros se comunicando e cooperando em rede. A colaboração facilita o compartilhamento de informações e conhecimentos, e resulta dele. As organizações não melhoram ou inovam sozinhas, mas sobre 
informações e conhecimentos acumulados dentro e fora delas. Cabe então pensar nas relações entre colaboração, relações intersubjetivas para a melhoria da qualidade e inovação (LIMA; LIMA; MOREIRA, 2019, p. 52).

\section{DISCURSO, PROBLEMA E RECONSTRUÇÃO RACIONAL EM HOSPITAIS}

Com o aumento da produção do conhecimento acompanhado do avanço das tecnologias de informação e comunicação, é urgente que a capacidade de responder às necessidades de informação dos profissionais de saúde venha junto com confiabilidade, precisão e rapidez. As pesquisas e investimentos em inovação na área da saúde têm ocorrido em velocidade cada vez maior e em diferentes frentes, vários programas são instituídos no intuito de se detectar, prevenir e tratar as doenças. Essas pesquisas geram uma gama de produções científicas que são publicadas em forma de livros e artigos científicos, dentre outros formatos, colaborando, assim com o avanço da ciência. Esse aumento do volume de documentos, junto com a necessidade dos profissionais da saúde de encontrarem a melhor evidência disponível, têm alterado o perfil de atendimento e(ou) do profissional que atenda e responda por essas demandas.

Nesse contexto está a figura do bibliotecário especialista na área da saúde, um profissional capaz de responder e traduzir as indagações dos profissionais da referida temática. O bibliotecário clínico, como também é chamado, é o elo entre a melhor evidência de saúde e o profissional que a deseja.

Para o alcance de um resultado eficaz dessa atividade de mediação, também é importante ter os conhecimentos teóricos educacionais básicos. Paulo Freire, teórico da educação, sustenta em sua concepção filosófica que a educação é instrumento libertador e humanizador, "educação como prática da liberdade” (FREIRE, 2014. p. 12). O bibliotecário explora ao máximo as potencialidades de uma educação libertadora ao fazer a entrevista com seu usuário. Assim como se dá na proposta de educação humanista de Freire (2014), com destaque para saber ouvir as palavras do educando, assim o bibliotecário, ao extrair de seu usuário suas percepções, inquietações com base em suas questões de pesquisa. Dentro desse bojo de informações, o bibliotecário a transforma e constrói junto com o profissional da saúde em uma pergunta de pesquisa clara e respondível. Com todos os dados colhidos é organizada a estratégia de busca que compreenda o problema formulado.

A experiência multidisciplinar; a ligação com a prática clínica, tornando-se membro ativo junto às equipes; habilidades de busca para recuperação da informação; a capacidade de construir relações para facilitar o diálogo e sintonia com a equipe. De acordo com Freire (1985), 
a prática da educação como um ato dialógico e comunicativo através da linguagem é um elemento mediador no processo da aprendizagem, é esse desafio que o bibliotecário deve assumir. Com a função de gestor de informação e de facilitador no uso de dados e evidências, otimizando, assim, o processo de acesso à informação clínica científica.

Paulo Freire, então, entende a aprendizagem como problematização, pois pressupõe uma cognição não condescendente e crítica. Habermas, por sua vez, "pensa a aprendizagem como reconstrução racional, em que eu e o outro interagimos, eu reconheço e me coloco no lugar do outro e nos entendemos em torno de melhor argumento" (LIMA; LIMA; GÜNTHER, 2019, p. 2011).

O Discurso é uma forma especial de agir comunicativo. Nele os falantes buscam resolver as controvérsias através da argumentação e da decisão em torno do melhor argumento. $\mathrm{O}$ Discurso é o uso público da razão que visa produzir entendimento e orientar o agir. É a ponte entre os diferentes argumentos de distintos participantes em busca de sincronicidade e, por conseguinte, de entendimento mútuo que norteia a prática cotidiana. E o faz mediante a problematização e a reconstrução racional.

O processo discursivo implica em crítica dos fatos no mundo da vida. A capacidade de ver os problemas na paisagem é uma condição para esse processo. A problematização é a dimensão cognitiva da aprendizagem, que busca soluções racionais e as amplia de modo permanente. Buscar soluções e ampliar racionalidade são as faces da aprendizagem, em que há construção da subjetividade e da intersubjetividade.

Os estudos no campo da linguagem ampliam as formas do discurso favorecendo novos debates sobre o poder da comunicação. Habermas (1997, p. 74) já dizia que "O entendimento fora de códigos específicos passa a ser tido como coisa ultrapassada”, isto é, a linguagem exerce papel crucial na comunicação que, por sua vez, é imprescindível à construção de entendimento.

As bibliotecas em hospitais são organizações onde se integra o pensar de seus usuários. Educar, compartilhar informação e conhecimento, são processos, em que se deve estabelecer uma conexão. A comunicação estabelece esse elo. O profissional bibliotecário, como agente de mudança, amplia seu papel ao atuar no desenvolvimento da competência informacional da equipe médica que auxilia. Uma orientação que vai além das redes técnicas informacionais, um processo de aprendizagem organizacional, onde são construídas redes de sentidos, onde o discurso apoiado no agir comunicativo, estabelece novas relações entre a linguagem e as tecnologias da informação para promover a sua aplicação na solução de problemas comunicativos da equipe. O estabelecimento de redes de sentidos para a tradução da 
necessidade de informação da equipe médica e os aproxima dos serviços da biblioteca e otimizam os fluxos de conhecimento e o aprendizado interativo.

Essa aprendizagem com interação permite que o grupo envolvido assuma seus lugares como sujeitos ativos no processo de aprendizagem. Essa capacidade cognitiva é estimulada pelo profissional, no caso o bibliotecário, no momento do diálogo, do tecer as argumentações, das considerações para a produção de sentido, e, nesse caso do compartilhamento de saberes.

Associar aprendizagem e Discurso por meio da problematização viabiliza de modo especial o processo de reconstrução que, por sua vez, leva a um entendimento superlativo. No sentido habermasiano, reconstruir "significa refletir sobre as regras que têm de ser supostas para que seja possível a própria compreensão do sentido que é construído social e simbolicamente" (LIMA; LIMA, 2019, p. 108). Ora, daqui depreende-se que o acesso adequado à informação qualificada e a decorrente construção do entendimento permite à equipe hospitalar suporte efetivo à conduta em prol da saúde. Aqui há a união de profissionais da informação subsidiando profissionais da saúde para a recuperação do paciente (que também compõe a construção do entendimento).

A reconstrução racional acontece quando os falantes, em seu agir intersubjetivo se entendem e fazem acordos. Esses acordos se fazem em torno de argumentos que consideram razões ampliadas. Este desdobramento da crítica permite deliberações teóricas e práticas não apenas legítimas, mas também numa relação simétrica entre os sujeitos.

A reconstrução surge como um método que busca revelar estruturas profundas vistas como precondições de práticas (linguísticas) de atores sociais. Ela assinala um conjunto de regras fundamentais que são consideradas como condições primárias de ações racionais (sentenças linguísticas). [...] Um sujeito que age (usuário da linguagem) pode ser capaz de desenvolver argumentos coerentes num discurso sem conhecer as regras que ele necessariamente segue quando realiza esses atos: ele sabe "como" realizar ações sem conhecer as precondições que possibilitam essas ações. [...] Em outras palavras, a reconstrução racional explicita um conhecimento implícito e transforma o "saber como" em um "saber que". Por causa do seu caráter implícito e pré-reflexivo, esses sistemas de regras correspondem, de acordo com Habermas, a uma forma "pura" do conhecimento (VOIROL, 2012, p. 91-92).

Reconstruir discursivamente significa a busca pela reflexão das regras, estruturas e processos que pautam o processo decisório e que são o princípio para a compreensão do sentido. Reconstruir racionalmente as estruturas profundas que geram as decisões viabiliza a investigação da racionalidade própria das regras usadas em um determinado momento em um contexto definido (LIMA; LIMA, 2019). 
Nobre e Repa (2012) orientam que o projeto reconstrutivo de Habermas tem como intuito elucidar regras e processos sociais em que objetos simbólicos emergem e ganham sentido nas relações sociais. Consequentemente, a reconstrução habermasiana implica reflexão sobre regras para que seja erigido, tanto social quanto simbolicamente, o sentido.

Deste modo, a reconstrução habermasiana se baseia em práticas implícitas ou esquemas cognitivos, considera os sistemas anônimos de regras como uma base geral de referência para todos os sujeitos e explicita os sistemas intuitivos de conhecimento e de competências sem que isso tenha consequências práticas. Assim se constrói o entendimento. Com efeito, minimiza-se a falsa consciência que advêm das experiências inconscientes mediante a reflexividade e reduzse o impacto do sujeito individual e particular. Habermas busca condições universais de comunicação bem-sucedida, as quais advêm do Discurso (VOIROL, 2012).

A reconstrução discursiva deve partir da visão reflexiva e crítica, isto é, deve se propor um mecanismo que permita a abertura para a escuta dos críticos e, assim, a problematização esteja presente nas interações. A abertura à crítica direciona para ampliar o campo perceptivo, pois "a partir da construção de um entendimento baseado na discursividade, há uma tentativa de estabelecimento de uma 'ponte' com a complexidade excluída e existente no mundo da vida" (LIMA; LIMA, 2019, p. 109). Ou seja, a reconstrução discursiva é uma prática restauradora de sentido e de entendimento.

Para observarmos a reconstrução discursiva de modo mais aplicado, resgatamos Voirol (2012, p. 92) que elucida que "o processo de reconstrução depende de um ponto de vista teórico afastado do âmbito prático das atividades ordinárias". No contexto hospitalar, pode-se pensar no bibliotecário como o agente que brinda a prática médica com o ponto de vista afastado das atividades ordinárias (informação qualificada).

Cabe dizer que o procedimento reconstrutivo é possível apenas na medida em que se consegue refletir sistematicamente sobre as regras tácitas e o conhecimento implícito a que nos referimos em nossas práticas cotidianas (VOIROL, 2012), o que é viabilizado pela prática discursiva e pela aprendizagem, isto é, em essência, pelo processo comunicativo.

A reconstrução discursiva está, portanto, fundamentada em uma atitude que tem o processo comunicativo como chave. Tal acionamento rompe com a atitude objetivante, típica de um observador de regularidades empíricas (neste estudo, papel desempenhado pelo profissional da saúde). Em contraposição, os atores, então, devem agir comunicativamente "buscando encontrar uma definição comum para sua situação, assim como, em se entender sobre temas e planos de ação existentes interna e externamente a organização" (LIMA; LIMA, 2019, p. 109). 
Isso significa que a reconstrução deve expor não um conjunto de ilusões de um sujeito passivo, mas as competências práticas dos sujeitos atuantes envolvidos em atividades usuais que podem ser consideradas como partilhadas em comum. De acordo com Habermas, qualquer sujeito atuante "possui" necessariamente competências práticas, pois estas são condições de uma socialização normal numa sociedade humana. Em outras palavras, a "reconstrução racional" concebida por Habermas não deve revelar um conjunto de conhecimentos intuitivos válidos sob certas circunstâncias limitadas, mas um sistema de competências universalmente válidas, tidas como precondição fundamental das práticas humanas (VOIROL, 2012, p. 92-93).

Para tanto, faz-se necessário submeter continuamente as práticas existentes à crítica e à transformação reflexiva, superando, então, a imunização existente nos seus conteúdos normativos e formas de funcionamento (LIMA; LIMA; GÜNTHER, 2019). Entende-se que essa argumentação aqui proposta acerca da construção dialógica restauradora fortalece processos mais integradores e integrais, onde a atuação do bibliotecário nos hospitais vai além de propiciar o acesso da equipe clínica à informação. Ao proporcionar informação precisa, rápida e efetiva, o bibliotecário passa a ampliar o espectro da atuação em saúde, qualificandoa e impactando superlativamente a prática hospitalar.

\section{CONSIDERAÇÕES FINAIS}

O cenário social, econômico e cultural modificou-se diante da evolução das tecnologias, do avanço dos métodos aplicados à medicina e as inovações geradas a partir desses processos. Existe ampla gama de informações produzidas dispersas em vários ambientes. É necessário gestão da informação científica e organização para disseminá-las. As organizações hospitalares, permeadas pela imunização do paciente, carecem agora de higienização de seus próprios processos para gerar espaço à competência colaborativa do bibliotecário clínico.

Nesse contexto, o bibliotecário possui perspectivas promissoras de ações na equipe médica/saúde, pois pode apoiar a demanda informacional, na obtenção de tempo e na colaboração junto com a equipe de saúde e pacientes. Essencialmente qualificando atividades de busca, pesquisa, organização e disseminação da informação e, de modo mais amplo, como coagente da construção de sentido na prática clínica. Assim, atua no apoio e na busca de informações em saúde através do acervo e serviços informacionais criados e implementados para o suporte em tomada de decisão clínica e sobre diagnósticos dos pacientes. Faz com que os serviços informacionais atendam diretamente e antecipem as lacunas das necessidades informacionais, tanto dos médicos quanto dos pacientes. 
O bibliotecário tem seu agir informacional como contributivo à reconstrução racional hospitalar e pode criar nessas ambientes interfaces de serviços informacionais com um olhar mais apurado, especificando e especializando no quesito informacional das atividades de mediação da informação sobre saúde, diversificando seletivamente as informações relevantes para a equipe de saúde como para os pacientes e demais consumidores de informação. Ademais, favorece a comunicação e as relações sociais.

A competência comunicativa do bibliotecário em hospitais é o amálgama formado pelas diferentes capacidades do interagir mediado pela linguagem, do discurso crítico e de fazer acordos em torno dos melhores argumentos. Esta competência não está vinculada apenas as habilidades profissionais do bibliotecário de organização do conhecimento, de gestão da informação ou de comunicação científica. Elas são parte do agir comunicativo e do discurso.

Por outro lado, a competência comunicativa dos bibliotecários não pode estar focada apenas na recuperação de informação dentro de equipes orientadas por evidências científicas. Em prol da integridade do processo discursivo, os bibliotecários são convidados a intervir de modo crítico. Assim, os bibliotecários nos hospitais devem participar destes sistemas complexos para oferecer uma perspectiva interna que, além de suas habilidades profissionais técnicas, têm a potência de mudar ou ampliar a racionalidade com a crítica, o discurso e a aprendizagem.

Para o profissional de saúde em sua prática assistencial é árduo acompanhar atualizado o crescimento informacional. É necessário que os gestores hospitalares estejam abertos à um novo panorama, a formação de um ambiente favorável ao apoio de práticas que levem à informação e compartilhem o saber. Assim, fortalece-se a atuação do bibliotecário, que evidencia a necessidade de ter informações pertinentes e atuais, em ter fontes confiáveis e acervo disponível, de fácil acesso para não perder tempo e recursos. Os profissionais bibliotecários pesquisados incontestavelmente reconhecem a importância de seu trabalho como apoio à equipe médica.

Este estudo evidencia que o acesso adequado à informação qualificada e seu consequente pleno entendimento permite à equipe hospitalar suporte efetivo à conduta em prol da saúde. A competência comunicativa une profissionais da informação e profissionais da saúde para a recuperação do paciente (que também é chamado à construção do entendimento). A relação simétrica entre os sujeitos é condição primordial para agir o intersubjetivo, em que há argumentos e acordos pautados em razões ampliadas e deliberações legítimas.

A reconstrução discursiva é uma prática restauradora de sentido e de entendimento. É possível apenas mediante problematização sistemática das regras, processos e estruturas, ainda 
que sejam primariamente tácitos, mesmo que inicialmente estejam implícitos. A competência comunicativa pressupõe atividades cotidianas pautadas na prática discursiva e na aprendizagem.

Assim, realizar o trabalho com a informação científica em saúde é uma forma de cuidar da saúde do paciente. Os processos e serviços informacionais para atender os profissionais de saúde e os pacientes visam trazer alguma forma de melhoria no andamento cirúrgico, em leitos dos hospitais e no acolhimento em uma hora de dificuldade. Como também na mediação da informação relevante e de qualidade em cada caso pode atenuar as aflições ligadas a esse momento. Um bom trabalho informacional que pode salvar vidas, especialmente se realizado comunicativamente. Admitir e compreender as relações multiprofissionais na equipe de saúde, dentre eles, o bibliotecário como mediador da informação em saúde, criador e aperfeiçoador dos serviços informacionais. Esse profissional é o elo entre a informação científica e as práticas do dia a dia e a socialização, intensificando e dinamizando as práticas sociais e comunicativas. 


\section{REFERENCIAS}

FOUCAULT, Michel. O nascimento da clínica. Rio de Janeiro: Forense Universitária, 1987.

FREIRE, P. Educação como prática da liberdade. 36a ed. São Paulo: Paz e Terra, 2014.

FREIRE, P. Extensão ou comunicação. Rio de Janeiro: Paz e Terra, 1985.

GOMES, H. F.; VARELA, A. V. Mediação da informação na área da medicina:

possibilidades de interlocução entre os saberes científico, profissional e sociocultural.

Perspectivas em Ciência da Informação, v. 21, n. 1, p. 3-22, jan/mar. 2016. Disponível em: http://portaldeperiodicos.eci.ufmg.br/index.php/pci/article/view/1529. Acesso em: 22 jul. 2019.

GRACIOSO, L. de S. Considerações sobre filosofia da linguagem e ciência da informação: jogos de linguagem e ação comunicativa no contexto das ações de informação em tecnologias virtuais. In: FREIRE, G. H. de A. (org.). A responsabilidade social da Ciência da informação. João Pessoa: Ideia, 2009.

HABERMAS, J. Consciência moral e agir comunicativo. Rio de Janeiro: Tempo Brasileiro, 1989.

HABERMAS, J. Direito e democracia: entre faticidade e validade, v. II. Rio de Janeiro: Tempo Brasileiro, 1997.

HABERMAS, J. Pensamento pós metafísico: estudos filosóficos. Rio de Janeiro: Tempo Brasileiro, 1990.

HABERMAS, J. Teoria do Agir Comunicativo. Racionalidade da ação e racionalização social volume I. Tradução Paulo Astor Soethe; revisão da tradução Flávio Beno Siebeneichler. - São Paulo: Editora WMF Martins Fontes, 2012.

LIMA, C. R. M.; LIMA, J. R. T. Discurso, reconstrução racional e administração humanística das organizações. In: LIMA, C. R. M. (org.). Habermas, Discurso e Organizações: administração discursiva. Rio de Janeiro: Salute, 2019.

LIMA, C. R. M.; LIMA, J. R. T.; GÜNTHER, H. F. Competência comunicativa para problematização e aprendizagem em organizações. P2P \& Inovação, Rio de Janeiro, v. 5, n. 2, p. 200-219, 2019.

LIMA, C. R. M.; LIMA, J. R. T.; MOREIRA, F. K. Problematização e racionalização discursiva dos processos produtivos em organizações. In: LIMA, C. R. M. (org.). Habermas, Discurso e Organizações: administração discursiva. Rio de Janeiro: Salute, 2019.

NOBRE, M.; REPA, L. (org.) Habermas e a reconstrução: sobre a categoria central da teoria crítica habermasiana. Campinas, SP: Papirus, 2012.

SILVA, F. M. S.; FERNANDES, G. C.; LIMA, C. R. M. de. Competência comunicativa: uma competência administrativa para o bibliotecário universitário contemporâneo. Informações e Profissões, Londrina, v. 2, n. 2, p. 119-133, 2013. Disponível 
G INOVAÇÃo

em:http://www.uel.br/revistas/uel/index.php/infoprof/article/view/17205. Acesso em: 28 jun. 2019.

VOIROL, O. Teoria crítica e pesquisa social: da dialética à reconstrução. Novos Estudos Cebrap, n. 93, p. 81-99, jul. 2012. 